\title{
Article \\ Transcriptional Organization of the Salmonella Typhimurium Phage P22 pid ORFan Locus
}

\author{
Sanne Wolput ${ }^{1}$, Angela Makumi ${ }^{1,+}{ }^{\oplus}$, Laura Wicke ${ }^{2}{ }^{\oplus}$, Leonard E. Bäcker ${ }^{1}$, William Cenens ${ }^{1}$, Yves Briers ${ }^{3}{ }^{\circ}$, \\ Nicolas A. Wenner ${ }^{4, \ddagger}$, Siân V. Owen ${ }^{4, \S} \mathbb{D}$, Jay C. D. Hinton ${ }^{4} \mathbb{D}$, Rob Lavigne ${ }^{2}$ and Abram Aertsen ${ }^{1, *(1)}$
}

1 Laboratory of Food Microbiology, Department of Microbial and Molecular Systems, KU Leuven, 3000 Leuven, Belgium; sanne.wolput@kuleuven.be (S.W.); A.Makumi@cgiar.org (A.M.); leon.backer@kuleuven.be (L.E.B.); w.cenens@gmail.com (W.C.)

2 Laboratory of Gene Technology, Department of Biosystems, KU Leuven, 3000 Leuven, Belgium; laura.wicke@kuleuven.be (L.W.); rob.lavigne@kuleuven.be (R.L.)

3 Laboratory of Applied Biotechnology, Department of Biotechnology, Ghent University, 9000 Ghent, Belgium; Yves.Briers@UGent.be

4 Institute of Infection, Veterinary and Ecological Sciences, University of Liverpool, Liverpool CH64 7TE, UK; nicolas.wenner@unibas.ch (N.A.W.); sian@hms.harvard.edu (S.V.O.); Jay.Hinton@liverpool.ac.uk (J.C.D.H.)

* Correspondence: abram.aertsen@kuleuven.be; Tel.: +32-16-32-17-52

† Current address: Animal and Human Health Program, International Livestock Research Institute, Nairobi 00100, Kenya.

$\ddagger$ Current address: Biozentrum, University of Basel, 4056 Basel, Switzerland.

$\S$ Current address: Department of Biomedical Informatics and Laboratory of Systems Pharmacology, Harvard Medical School, Boston, MA 02115, USA.

check for updates

Citation: Wolput, S.; Makumi, A.; Wicke, L.; Bäcker, L.E.; Cenens, W.; Briers, Y.; Wenner, N.A.; Owen, S.V.; Hinton, J.C.D.; Lavigne, R.; et al. Transcriptional Organization of the Salmonella Typhimurium Phage P22 pid ORFan Locus. Int. J. Mol. Sci. 2022, 23, 1253. https://doi.org/ 10.3390/ijms23031253

Academic Editor: Alicja Wegrzyn

Received: 29 December 2021

Accepted: 21 January 2022

Published: 23 January 2022

Publisher's Note: MDPI stays neutral with regard to jurisdictional claims in published maps and institutional affiliations.

Copyright: (c) 2022 by the authors. Licensee MDPI, Basel, Switzerland. This article is an open access article distributed under the terms and conditions of the Creative Commons Attribution (CC BY) license (https:// creativecommons.org/licenses/by/ $4.0 /)$.

\begin{abstract}
Many phage genes lack sequence similarity to any other open reading frame (ORF) in current databases. These enigmatic ORFan genes can have a tremendous impact on phage propagation and host interactions but often remain experimentally unexplored. We previously revealed a novel interaction between phage P22 and its Salmonella Typhimurium host, instigated by the ORFan gene pid (for phage P22 encoded instigator of $d g o$ expression) and resulting in derepression of the host dgoRKAT operon. The pid gene is highly expressed in phage carrier cells that harbor a polarly located P22 episome that segregates asymmetrically among daughter cells. Here, we discovered that the pid locus is fitted with a weak promoter, has an exceptionally long $5^{\prime}$ untranslated region that is instructive for a secondary pid mRNA species, and has a $3^{\prime}$ Rho-independent termination loop that is responsible for stability of the pid transcript.
\end{abstract}

Keywords: phage-host interactions; Salmonella Typhimurium; phage P22; pid ORFan locus; dgoRKAT operon

\section{Introduction}

With an estimated presence of around $10^{31}$ virions, viruses of bacteria (i.e., bacteriophages or phages) are the most ubiquitous entities in our biosphere and have an unrivalled impact on the ecology and evolution of their hosts [1,2]. Furthermore, the many different phage species that exist constitute a tremendous sequence space that we have only just begun to explore [3]. Indeed, while sequencing efforts are massively sampling this space, it is clear that many phage genes lack homologs in the currently existing databases and have not been investigated experimentally [4-6]. However, these unknown phage genes (also referred to as phage ORFans) can profoundly impact phage propagation $[7,8]$ and host interactions $[9,10]$.

As such, the existence of many phage ORFan genes underscores that the full complexity of phage-host associations and interactions has yet to be established, even in well-studied model systems such as the temperate lambdoid phage P22 and its Salmonella Typhimurium host. Indeed, we have previously revealed the existence of a cryptic carrier 
state association of P22 that deviates from its strictly lytic or lysogenic proliferation [11]. We found that during the path towards lysogenisation of its host, P22 is able to form a polarly-located episome that persistently becomes segregated asymmetrically between daughter cells. In carrier cells inheriting this P22 episome, a P22 ORFan gene termed pid (for phage $\underline{P} 22$ encoded instigator of $\underline{d g o}$ expression [12]) is highly expressed. The corresponding Pid protein derepresses the host dgoRKAT operon, an operon that drives D-galactonate metabolism [12], although the impact of this Pid/dgo interaction and the regulation of the pid locus remain elusive.

The presence of the pid locus remained unnoticed for decades, until its identification as a functional gene, located between the orf25 and orf80 of P22 [12]. Although found in the late region of the P22 genome, the orientation of pid opposes the main late promoter. In this study, we report the findings of a genetic screen designed to reveal key regulatory functions of the P22 pid locus.

\section{Results}

\subsection{Genetic Screen for Functional Mutations in the P22 pid Locus}

To functionally characterize the P22 pid locus, we set up a genetic screen in which a DES-mutagenized P22 population was plaqued on LB X-Gal on the LT2K7 indicator strain (i.e., LT2 dgoT::MudK; [12]) that reports on derepression of the $d g o$ operon by producing the LacZ reporter protein. We chose plaques with an altered degree of blue color resulting from LacZ activity on the X-Gal and sequenced the pid locus of the corresponding phage. We excluded clear plaques from this screen since previous research revealed that obligate lytic variants of P22 do not enter the carrier state and do not express Pid, and therefore do not support the Pid/dgo interaction [12]. Our screen revealed (i) two clones (P22-pid ${ }^{C-183 A}$ and P22-pid ${ }^{\mathrm{C}-182 A}$ ) that had more intense blue coloration than wild-type P22 (i.e., P22wt) and that carry mutations far upstream of the pid open reading frame (ORF), (ii) one blue-

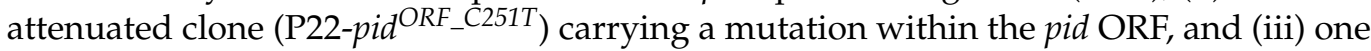
blue-attenuated clone (P22-pidterm_G292A) carrying a mutation downstream of the pid ORF (Figure 1).

(a)

(b)

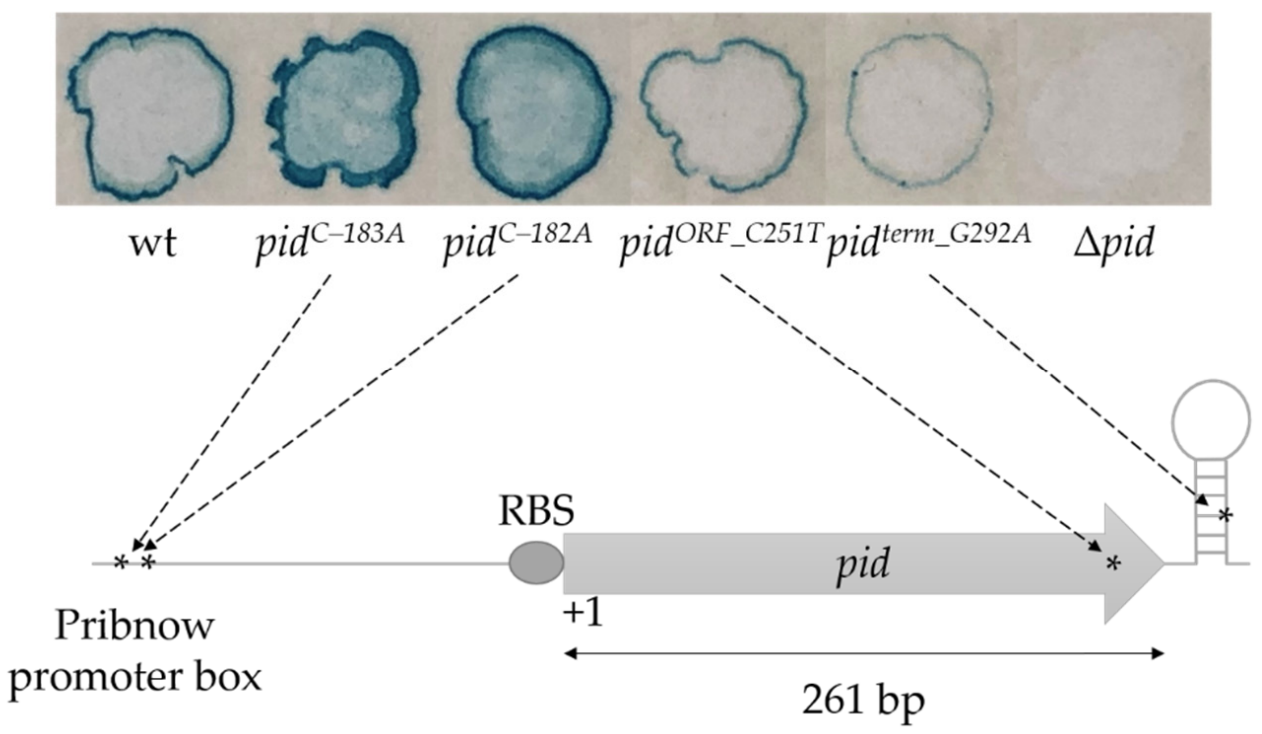

Figure 1. DES-mutagenesis screen revealed functional mutations in the P22 pid locus. Selected DES-mutagenized P22 clones plaqued on a lawn of the LT2K7 indicator (LT2 dgoT::MudK) on LB $\mathrm{X}-\mathrm{Gal}$ in which blue coloration reports on LacZ activity (panel (a)) and the corresponding mutation in the pid locus (panel (b)). Numbering of the mutations (indicated as *) is relative to the pid start codon. 
Of the two mutants attenuated in the Pid/dgo interaction, one contained a C-to-T mutation located $251 \mathrm{bp}$ downstream of the pid start codon, leading to a T84M amino acid substitution in the C-terminal part of the Pid protein. However, since the structure-function relationship of Pid currently remains elusive, it was unclear as to how this amino acid change would compromise the Pid protein or the Pid/dgo interaction. The other mutant harbored a G-to-A mutation in the stem-loop structure downstream of the pid ORF (292 bp downstream of the pid start codon). This stem-loop (hairpin) structure is characterized by a $\mathrm{G}+\mathrm{C}$-rich stem followed by a stretch of poly $(\mathrm{T})$ on the sense strand, likely corresponding to a Rho-independent termination site [13]. Such sites play an important role in the termination mechanism by regulating the release of the transcript and RNA polymerase from the DNA template strand. The structure and dimension of such factor-independent termination sites can vary, and can influence transcript termination [14]. The G-to-A mutation in the G+Crich stem structure of pid might disrupt stem-loop formation and impact upon termination functionality and mRNA stability.

\subsection{Characterization of the P22 pid Promoter}

Since the above-mentioned mutations within and downstream of the pid ORF are likely loss-of-function mutations that simply compromise the Pid/dgo interaction, subsequent focus was placed on the upstream mutations that appeared to boost the interaction, i.e., P22-pid ${ }^{C-183 A}$ (with a C-to-A mutation, located 183 bp upstream of the pid start codon) and P22-pid ${ }^{C-182 A}$ (with a C-to-A mutation, located $182 \mathrm{bp}$ upstream of the pid start codon). Since both mutations were next to each other but far upstream of the pid start codon, the surrounding genetic context was scrutinized and predicted to be a promoter (97.1\% probability score via the PhagePromoter prediction tool integrated in the Galaxy framework, [15]). Moreover, a possibly eroded Pribnow promoter box (i.e., $5^{\prime}$-AATCCT- $3^{\prime}$ vs. the canonical $5^{\prime}$-TATAAT- $3^{\prime}$ ) was identified 181-186 bp upstream of the start codon where both the Cto-A mutations were situated ( $p$-value of 0.0014 via the SAPPHIRE 1 Promoter prediction tool, [16]).

To experimentally investigate the functionality of this putative promoter region, and of the $\mathrm{C}-182 \mathrm{~A}$ and $\mathrm{C}-183 \mathrm{~A}$ mutations, the fragment from 533 to $12 \mathrm{bp}$ upstream of the pid start codon from P22wt, P22-pid ${ }^{C-182 A}$, and P22-pid ${ }^{C-183 A}$ was cloned upstream of the $g f p$ gene in the pFPV25 promoter-probe vector [17] and assayed for GFP fluorescence production (Figure 2a). It was clear that the upstream region contained a basal promoter activity, which was boosted four- or sixfold by the $\mathrm{C}-182 \mathrm{~A}$ or $\mathrm{C}-183 \mathrm{~A}$ mutation, respectively (Figure $2 \mathrm{~b}$ ). These mutations change the region into $5^{\prime}$-AATCAT- $3^{\prime}$ or $5^{\prime}$-AATACT- $3^{\prime}$, respectively, and likely improve the functionality of the Pribnow promoter box by more closely resembling the optimal prokaryotic consensus sequence (i.e., $5^{\prime}$-TATAAT-3 ${ }^{\prime}$ ). Comparable studies on other genes have shown that mutations that make the Pribnow box more similar to the consensus sequence cause increased transcription of the downstream gene [17-19]. When the wild-type fragment cloned upstream of the $g f p$ reporter gene was shortened from its $5^{\prime}$ end (cf. $\mathrm{P}_{\text {pid }}{ }^{338}$ and $\mathrm{P}_{\text {pid }}{ }^{232}$; Figure 2a), promoter activity was lost when the 533 to $245 \mathrm{bp}$ fragment upstream of the pid start codon was removed (i.e., $\mathrm{P}_{\text {pid }}{ }^{232}$; Figure $2 \mathrm{c}$ ), suggesting no other promoters were present within the $244 \mathrm{bp}$ fragment immediately upstream of the pid ORF.

Finally, the plasmid data in Figure 2 also suggest that the wild-type pid promoter $\left(\mathrm{P}_{\text {pid }}{ }^{w t}\right)$ is active (or at least shows constitutive leaky expression), even in the absence of P22borne regulatory factors. Nevertheless, the leaky expression of pid from a P22wt lysogen (in the LT2K7 reporter) was insufficient to mount the Pid/dgo interaction (Figure 3). In contrast, a P22-pid ${ }^{C-183 A}$ lysogen with upregulated $\mathrm{P}_{\text {pid }}$ activity constitutively derepressed the $d g o$ operon (Figure 3). 
(a)

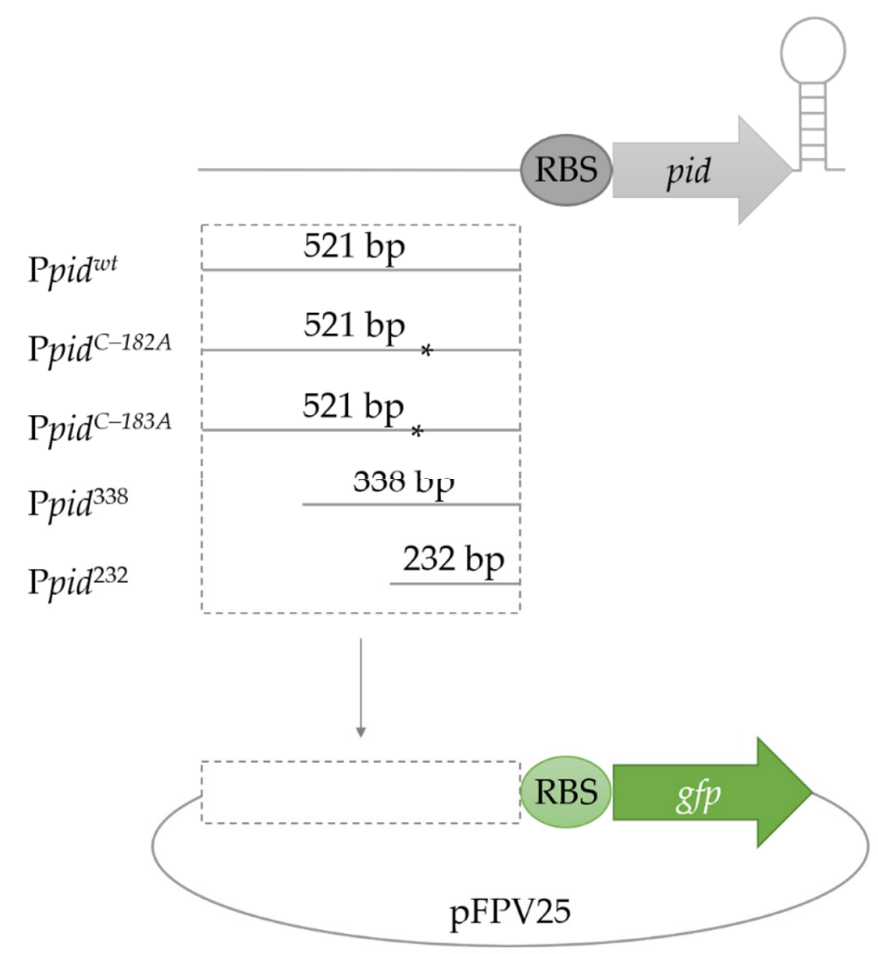

(b)

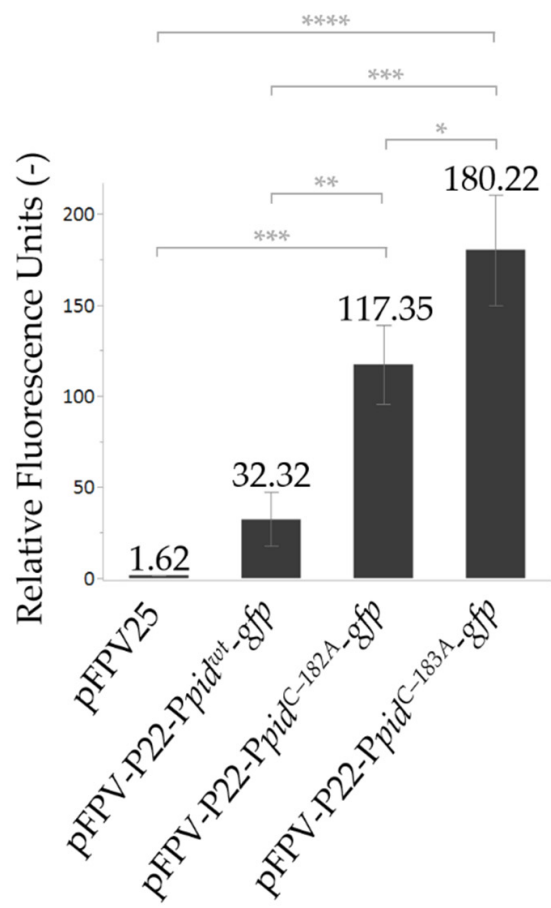

(c)

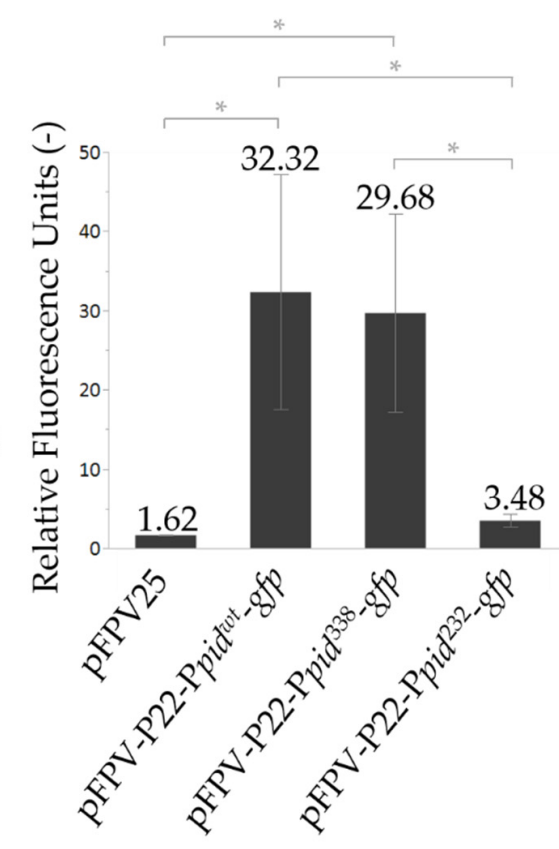

Figure 2. Assessment of the activity of the wild-type and mutant versions of the pid promoter (a) Schematic of the different pid promoter variants constructed upstream of the $g f p$ gene in the pFPV25 promoter probe plasmid. (b,c) GFP fluorescence stemming from AB-grown stationary phase cultures of LT2 equipped with the indicated reporter plasmids (panel $(\mathbf{b})$ : promoter mutations; panel (c): promoter truncations; as depicted in panel (a)). Please note that pFPV25 and pFPV-P22-P $\mathrm{P}_{\text {pid }}{ }^{\text {wt }}$ - $q f p$ are the same samples in panel $(\mathbf{b})$ and $(\mathbf{c})$. The mean fluorescence intensity relative to the $\mathrm{OD}_{600}$ value is represented in bars, and the mean value and the standard deviation of three biological repeats are shown. The empty plasmid (pFPV25) was included as a negative control. Significant differences (Tukey HSD test) are indicated by ${ }^{*}(p \leq 0.05),{ }^{* *}(p \leq 0.01),{ }^{* * *}(p \leq 0.001)$, and ${ }^{* * * *}(p \leq 0.0001)$. 


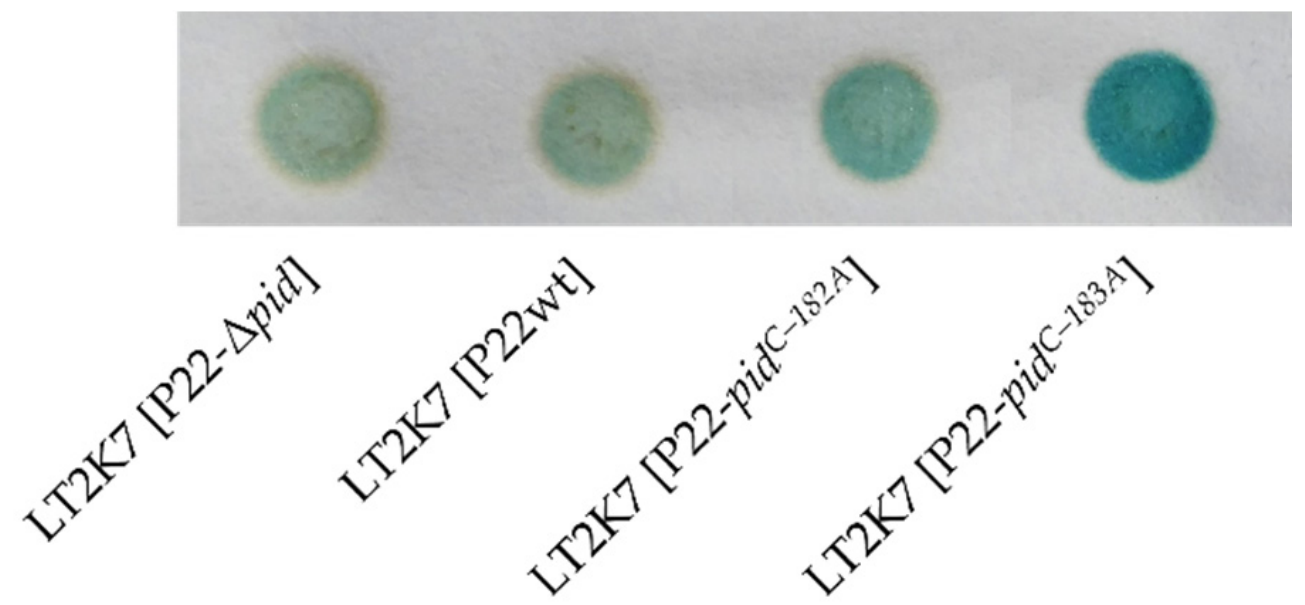

Figure 3. Pid/dgo interaction is absent during lysogeny. Spots of indicated LT2K7 (i.e., LT2 dgoT::MudK) lysogens grown on LB X-Gal in which blue coloration reports on LacZ activity, and thus dgo derepression.

\subsection{Characterization of the P22 pid Transcript}

Because the $\mathrm{P}_{\text {pid }}$ promoter appeared to be far upstream of the start codon, the pid transcript was predicted to have an extensive $5^{\prime}$ untranslated region $\left(5^{\prime} \mathrm{UTR}\right)$. Analysis of recent RNA-seq data from the Salmonella Typhimurium D23580 strain [6,20-22], which is naturally lysogenized with the BTP1 prophage that carries a pid locus identical to that of P22, revealed that the transcriptional start site (TSS) of $\mathrm{P}_{\text {pid }}$ was indeed located $174 \mathrm{bp}$ upstream of the pid start codon. This TSS location further confirms that the mutations identified in the DES-mutagenesis screen were located in the Pribnow box of the promoter region. Specifically, the C-182A and C-183A mutations modulated the -8 and -9 regions of the $\mathrm{P}_{\text {pid }}$ promoter (Figure 4). These data suggest that the TSS of the pid gene is located at nucleotide 40,880 on the genome of the P22 phage (NCBI Reference Sequence NC_002371.2).

The length of the pid transcript of P22 was examined in more detail via Northern blotting. To ensure pid expression, we exposed LT2 populations to a high MOI infection with wild-type or mutant P22 in order to favor lysogenisation and phage carrier state dynamics. After RNA extraction of these infected populations, Northern blotting involved either a ssDNA probe targeting the $5^{\prime} \mathrm{UTR}$ region of the pid mRNA or a ssDNA probe targeting the ORF region (Figure 5a). Following P22wt infection, the $5^{\prime}$ UTR probe revealed a transcript corresponding to the expected full-length of $476 \mathrm{bp}$ spanning from the TSS to the Rho-independent termination site (referred to as F-band) (Figure 5b, lane 1). Following infection with P22-pid ${ }^{\text {term-G292A }}$ (carrying the G-to-A terminator mutation 292 bp downstream of the pid start codon), the $5^{\prime}$ UTR probe only revealed a vague F-band (Figure 5b, lane 7), supporting our earlier hypothesis (Figure 1) that Rho-independent termination was important for pid mRNA stability. As expected, no pid transcript was observed following a negative control infection with P22- $\Delta$ pid, in which the pid ORFan had been removed (from the promoter region, $240 \mathrm{bp}$ upstream of the start codon, to the Rho-independent termination site) (Figure 5b, lane 6).

Interestingly, following P22wt infection, the ORF probe not only revealed the expected F-band, but also a slightly smaller fragment or transcript of between 350 and $400 \mathrm{bp}$ (referred to as smaller or S-band) (Figure $5 b$, lane 1). To further investigate whether the $5^{\prime}$ UTR was the cause of this S-band, we made truncations within the $5^{\prime}$ UTR of the pid locus in P22, from the $3^{\prime}$ end, while leaving the RBS of pid intact. The resulting mutant phages then contained the pid promoter region extending into either $109 \mathrm{bp}$ (P22-pid $\left.{ }^{423}\right), 57 \mathrm{bp}$ (P22-pid $\left.{ }^{371}\right)$, or $17 \mathrm{bp}\left(\mathrm{P} 22-\right.$ pid $^{331}$ ) of the $5^{\prime} \mathrm{UTR}$ region, followed by the pid RBS and ORF (Figure 5a). Northern blotting of the RNA extracted from high MOI infections with these truncated mutants yielded correspondingly shortened F-bands with both the $5^{\prime} \mathrm{UTR}$ or ORF 
probe (note that the annealing position of the $5^{\prime}$ UTR probe has been removed in P22-pid ${ }^{331}$ ) (Figure 5b, lanes 3-5). However, no parallel shortened S-bands could be detected with the ORF probe in these samples, suggesting that the $5^{\prime}$ UTR region 110-162 bp downstream of the transcriptional start site is responsible for this S-band.

\section{RNA-seq from early stationary phase (ESP) \\ dRNA-seq from early stationary phase (ESP_TEX)}
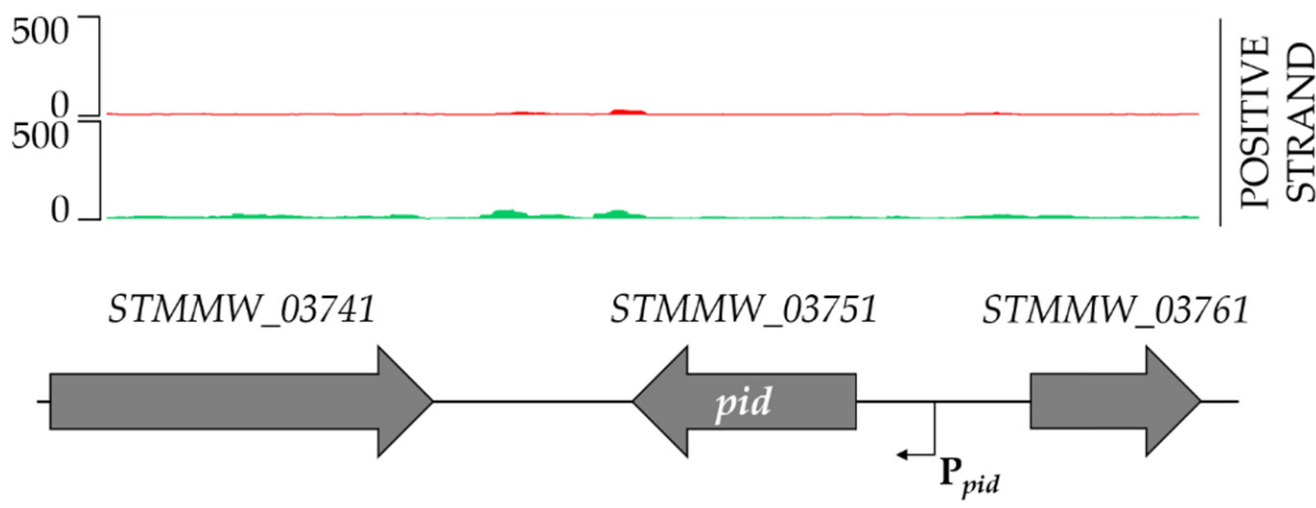

$50 \mathrm{bp}$

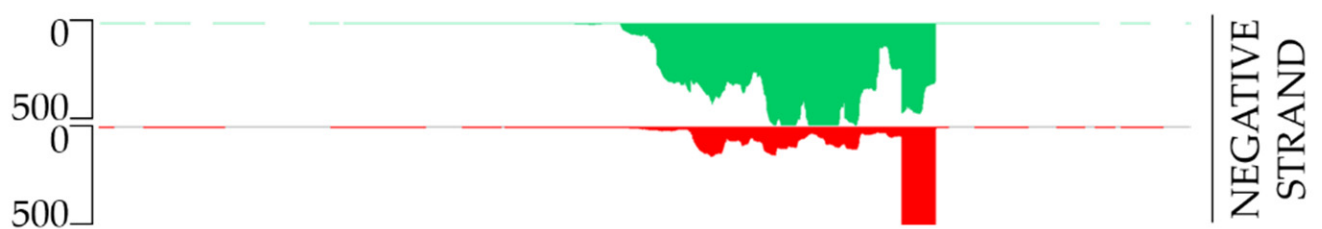

Figure 4. Identification of the transcription start site of the pid locus in prophage BTP1. RNAsequencing reads mapped to the positive and negative strand are shown in the upper and lower panels, respectively. The scale is $0-500$ normalized reads. Normalized RNA-seq data from early stationary phase are shown in green, and differential (d)RNA-seq data from early stationary phase are shown in red. dRNA-seq data are derived from RNA treated with terminator exonuclease (TEX) to enrich for transcripts carrying a $5^{\prime}$ triphosphate (primary transcripts), enabling more precise identification of transcription start sites. The TSS of pid (indicated with an arrow) was located $174 \mathrm{bp}$ upstream of the start codon of the pid coding sequence, at nucleotide position 389,658 on the D23580 chromosome. RNA-seq and dRNA-seq data were reinterpreted from Hammarlöf et al. (2018) [21].

This might in turn indicate that the $5^{\prime} \mathrm{UTR}$ region contains either secondary promoter elements or a processing site, leading to a smaller (S-band) transcript or fragment next to the full length (F-band) transcript. However, our promoter-probe studies detailed above (Figure 2) did not indicate additional promoters to be present closer to the pid ORF. Moreover, boosted pid expression via infection with P22-pid ${ }^{\mathrm{C}-183 A}$ (carrying the upregulating C-to-A mutation at -9 from the TSS) not only revealed the F- and S-bands with the ORF probe, but also a number of shorter fragments that might hint towards processing of the F-band (Figure 5b, lane 2). 
(a)

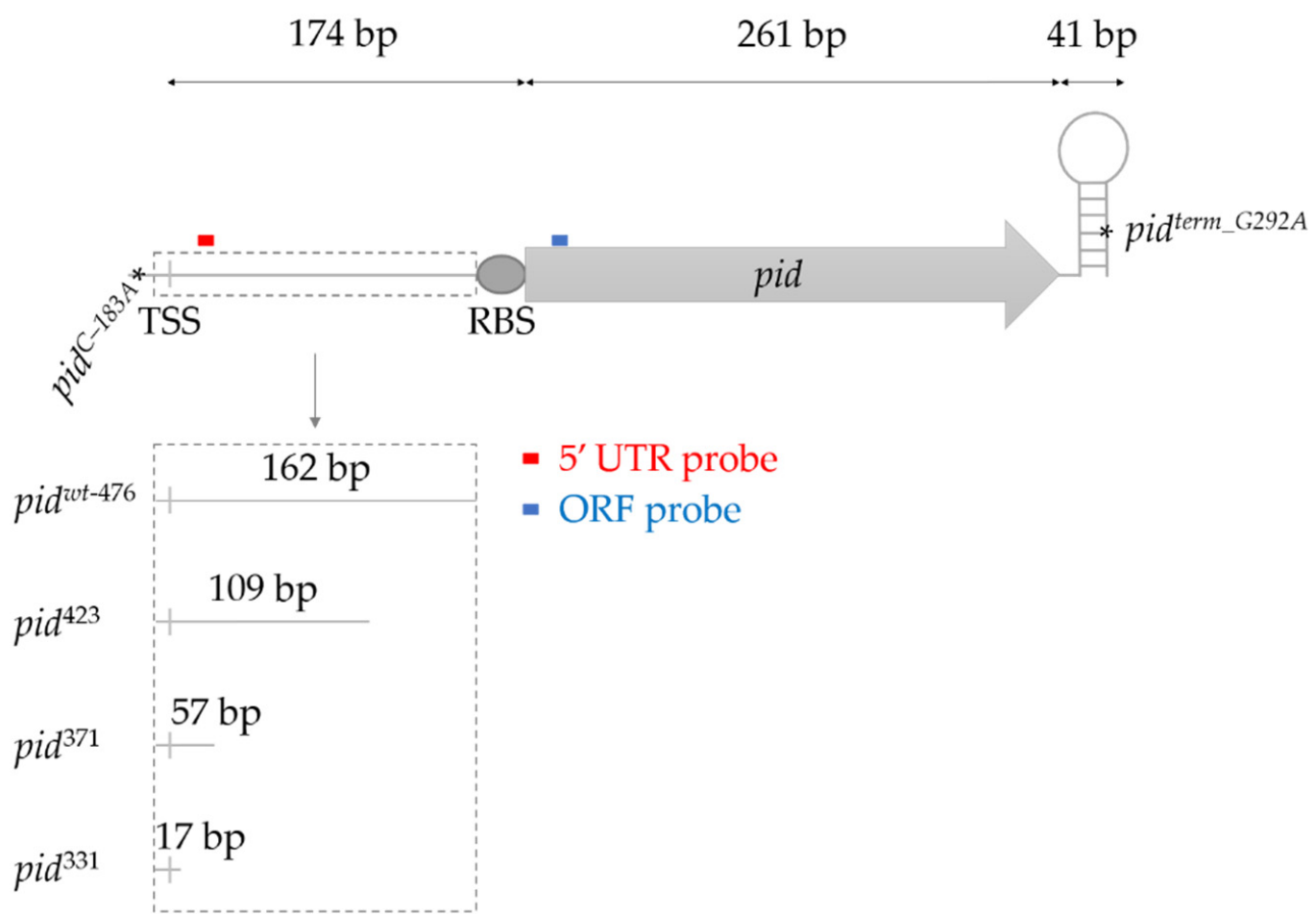

(b)

5'UTR probe
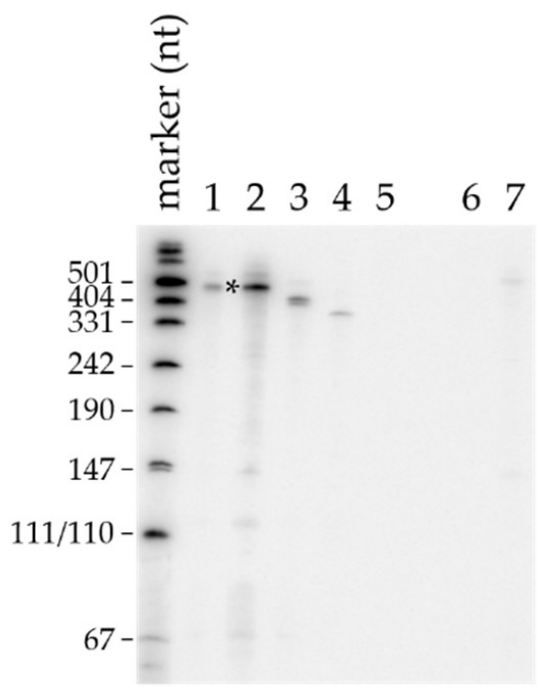

1.P22wt

2. P22-pid $\mathrm{C}-183 \mathrm{~A}$

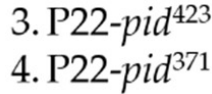

4. P22-pid ${ }^{371}$
ORF probe
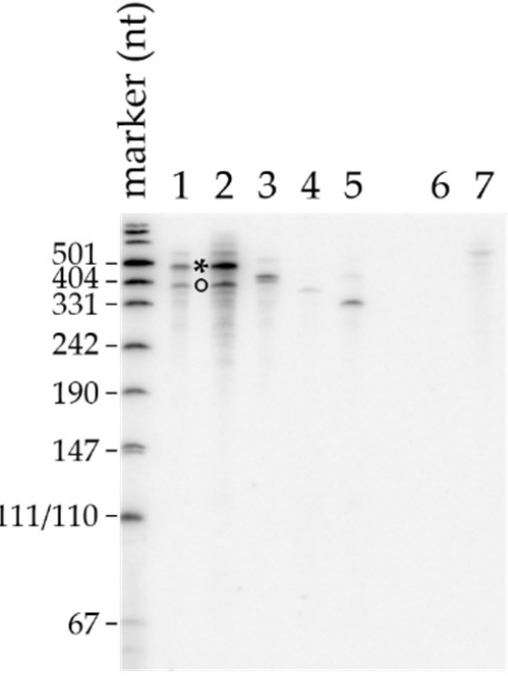

5. P22-pid ${ }^{331}$

6. P22- $\Delta$ pid
5 S rRNA
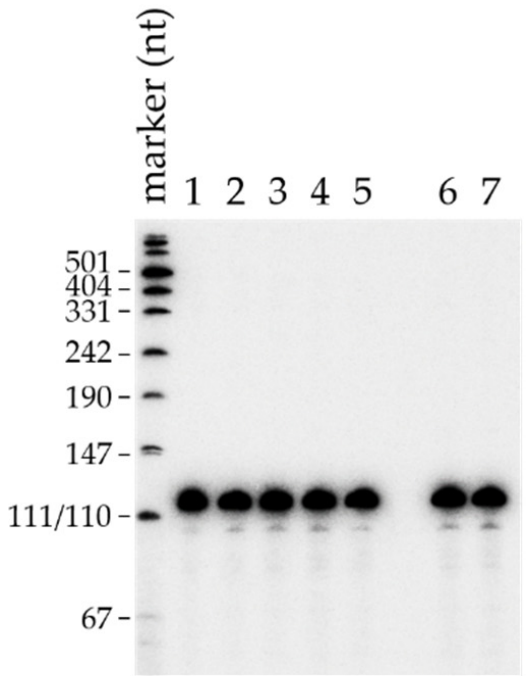

Figure 5. Visualization of the wild-type and mutant pid transcripts. (a) Scheme depicting the pid locus of P22wt and its indicated mutants and including the position of the ssDNA Northern blotting probes targeting either the $5^{\prime}$ UTR region or the ORF region of the transcript. (b) Representative images of the Northern blots of the pid transcript expressed by P22wt and the indicated P22 mutants during high MOI infection of LT2. Northern blots were labelled with either the 5'UTR (left panel) or ORF (middle panel) probe, and infection with P22- $\triangle$ pid was included as a negative control. The 5S rRNA loading controls are shown in the right panel. The F- and S-bands of lanes 1-2 are marked by ${ }^{*}$ and ${ }^{\circ}$, respectively. 


\section{Discussion}

Our investigation of the transcriptional organization of the P22 pid locus showed that the promoter was slightly leaky, and that expression of the pid transcript was mainly attenuated because of an eroded Pribnow box. Mutations rendering the Pribnow promoter box more similar to the prokaryotic consensus sequence significantly increased expression, even within lysogens (cf. constitutively derepressed Pid/dgo interaction), and even in the absence of any other P22-related factors (cf. reporter plasmid studies). This in turn suggests that the Pid overexpression observed during the phage carrier state of P22wt [11] could stem from P22 copy-number (i.e., pid dosage) effects during episome formation, rather than from more complex regulatory effects.

The pid promoter, however, was found to be located far upstream of the start codon, and TSS analysis confirmed the presence of an extensive $174 \mathrm{bp} \mathrm{5}$ UTR. While long $5^{\prime} \mathrm{UTR}$ regions have been linked to mRNA stability [23-25] and expression regulation [26] in bacteria and archaea, the prevalence of long $5^{\prime} \mathrm{UTR}$ in phages remains relatively uncommon and unexplored. The filamentous phage SW1, isolated from the deep-sea bacterium Shewanella piezotolerans WP3, contains two operons that have exceptionally long $5^{\prime} \mathrm{UTRs}$ (with lengths of 314 and $601 \mathrm{bp}$ ) that appear to thermoregulate the RNA stability of the transcripts [27]. Our results suggest that the $5^{\prime} \mathrm{UTR}$ of pid is responsible for the appearance of a second (and smaller) pid mRNA species, which could originate from an RNA processing site or the presence of a yet undetected secondary promoter. Although it currently remains to be resolved whether this smaller species serves a regulatory function, previous research has shown that mRNA processing in the $5^{\prime} \mathrm{UTR}$ region can affect transcript stability [28-30].

The $3^{\prime}$ UTR of pid contains a functional Rho-independent termination site, as suggested by the mutation attenuating the Pid/dgo interaction and pid transcript instability. Previous studies suggest that disruption of the stem-loop structure of Rho-independent termination sites abolishes terminator activity $[13,31,32]$. As a consequence, the mRNA is degraded and expression of the ORF is drastically decreased. This is exemplified by the $t I$ terminator of phage $\lambda$, in which disruption of the stem structure via the introduction of point mutations or deletions significantly reduces termination efficiency and decreases RNA stability [31,32]. Similarly, in E. coli, the disruption of a G+C-rich stem structure caused almost complete abolition of terminator activity and reduced expression of the crp gene due to increased mRNA degradation [13].

In summary, the expression regulation mechanism of the P22 pid ORFan gene was scrutinized, revealing a weak promoter region with an extensive $5^{\prime}$ UTR region. The latter may harbor a transcript processing or secondary promoter site, although its biological significance still remains elusive. Termination of the pid transcript is controlled by a Rho-independent terminator that is important for proper pid expression. As such, this study provides functional characterization of one of the few remaining ORFans in the P22 model phage.

\section{Materials and Methods}

\subsection{Strains, Phages, and Growth Conditions}

Bacterial strains, phages, and plasmids used in this study are listed in Table 1. Lysogeny broth (LB) medium [33] was used to culture bacteria, either as a broth or as agar plates after the addition of $1.5 \%$ (for spreading plates) or $0.7 \%$ (for soft agar plates) agar. Stationary phase cultures were obtained by growing cultures in LB for $15-20 \mathrm{~h}$ at $37^{\circ} \mathrm{C}$ under aerated conditions (agitation of $200 \mathrm{rpm}$ on rotary shaker). Exponential phase cultures were obtained by 1:100 dilution of stationary phase cultures in pre-warmed broth and further grown at $37^{\circ} \mathrm{C}$ to an $\mathrm{OD}_{600}$ between 0.2 and 0.3 . When required, the following chemicals (AppliChem GmbH, Darmstadt, Germany) were added to the growth medium at the indicated final concentrations: kanamycin $(50 \mu \mathrm{g} / \mathrm{mL})$, ampicillin $(100 \mu \mathrm{g} / \mathrm{mL})$, tetracycline $(20 \mu \mathrm{g} / \mathrm{mL})$, and 5-bromo-4-chloro-3-indolyl- $\beta$-D-galactopyranoside $(40 \mu \mathrm{g} / \mathrm{mL}$; X-Gal).

Phages were propagated on $S$. Typhimurium LT2 via the double agar overlay method in LB soft agar [34]. Three plaques were subsequently resuspended in $1 \mathrm{~mL}$ phage buffer 
(10 mM Tris- $\mathrm{HCl}(\mathrm{pH} 7.5), 10 \mathrm{mM} \mathrm{MgSO}{ }_{4}, 150 \mathrm{mM} \mathrm{NaCl}$ ) and incubated at $37^{\circ} \mathrm{C}, 1 \mathrm{~h}$, agitation of $200 \mathrm{rpm}$ on rotary shaker. A dilution series of the supernatant was plated with $100 \mu \mathrm{L}$ of stationary phase LT2 in soft agar (double agar overlay method) and incubated at $37^{\circ} \mathrm{C}$ for $15-20 \mathrm{~h}$. The soft agar layer was scraped off, chloroform was added, and the mixture was centrifuged for $10 \mathrm{~min}(6000 \mathrm{rpm})$. The supernatant was filter sterilized with $0.2 \mu \mathrm{m}$ PVDF membrane filters (Fisher Scientific, Hampton, NH, USA), and chloroform was added.

Table 1. Strains, bacteriophages, and plasmids used in this study.

\begin{tabular}{|c|c|c|}
\hline Name & Characteristic & $\begin{array}{l}\text { Source or } \\
\text { Reference }\end{array}$ \\
\hline \multicolumn{3}{|c|}{ Strains } \\
\hline LT2 & Salmonella Typhimurium wild-type & [35] \\
\hline LT2K7 & $\begin{array}{l}\text { LT2 } d g o T:: M u d K \$ \text { Insertion of } \mathrm{Mu} d \mathrm{~K} \text { in the } d g o \text { operon, resulting in a } \\
\text { translational lacZ reporter fusion to the } d g o T \text { gene }\end{array}$ & [12] \\
\hline LT2 [P22wt] & LT2 lysogenized with P22wt & This study \\
\hline LT2K7 [P22wt] & LT2K7 lysogenized with P22wt & This study \\
\hline LT2K7 [P22- $\Delta$ pid $]$ & LT2K7 lysogenized with P22- $\Delta$ pid & This study \\
\hline LT2K7 [P22-pid $\left.{ }^{C-183 A}\right]$ & LT2K7 lysogenized with P22-pid ${ }^{C-183 A}$ & This study \\
\hline LT2K7 [P22-pid $\left.{ }^{C-182 A}\right]$ & LT2K7 lysogenized with P22-pid ${ }^{C-182 A}$ & This study \\
\hline D23580 & Salmonella Typhimurium strain, naturally lysogenized with BTP1 prophage & [20] \\
\hline E. coli XTL298 & Contains the tet $A-s a c B$ cassette & [36] \\
\hline \multicolumn{3}{|c|}{ Bacteriophages } \\
\hline P22wt & Wild-type P22 phage & $\begin{array}{c}\text { Salmonella Genetic } \\
\text { Stock Centre } \\
(\text { SGSC })^{1}\end{array}$ \\
\hline P22- $\Delta$ pid & P22 with a deletion of the pid ORF and regulatory region & This study \\
\hline P22-pid ORF_C251T & P22 with a C-to-T point mutation, 251 bp downstream of the pid start codon & This study \\
\hline P22-pid term_G292A & $\begin{array}{l}\text { P22 with a G-to-A point mutation in the rho-independent terminator, } 292 \mathrm{bp} \\
\text { downstream of the pid start codon }\end{array}$ & This study \\
\hline P22-pid ${ }^{C-183 A}$ & P22 with a C-to-A point mutation, 183 bp upstream of the pid start codon & This study \\
\hline P22-pid ${ }^{C-182 A}$ & P22 with a C-to-A point mutation, $182 \mathrm{bp}$ upstream of the pid start codon & This study \\
\hline P22-pid 423 & P22 with a $3^{\prime}$ truncated $5^{\prime}$ UTR region of $109 \mathrm{bp}$, followed by an intact pid RBS & This study \\
\hline P22-pid 371 & P22 with a $3^{\prime}$ truncated $5^{\prime}$ UTR region of $57 \mathrm{bp}$, followed by an intact pid RBS & This study \\
\hline P22-pid 331 & P22 with a $3^{\prime}$ truncated $5^{\prime}$ UTR region of $17 \mathrm{bp}$, followed by an intact pid RBS & This study \\
\hline \multicolumn{3}{|c|}{ Plasmids } \\
\hline pKD46 & $\begin{array}{l}\text { Encodes } \lambda \text {-red recombineering genes under control of L-arabinose } \\
\text { inducible promoter }\end{array}$ & [37] \\
\hline pKD13 & Harbors frt-kan-frt site for construction of deletions by recombineering & [37] \\
\hline pCP20 & Encodes flippase (FLP) for recombining frt sites & [38] \\
\hline pFPV25 & Encodes promoterless GFP & [17] \\
\hline pFPV-P22-Ppid ${ }^{w t}-g f p$ & $\begin{array}{l}\text { Contains } 521 \text { bp of the } 5^{\prime} \text { regulatory region of P22wt upstream of } g f p \text { in the } \\
\text { pFPV25 plasmid }\end{array}$ & This study \\
\hline pFPV-P22-Ppid ${ }^{\mathrm{C}-182 A}-g f p$ & $\begin{array}{c}\text { Contains } 521 \text { bp of the } 5^{\prime} \text { regulatory region of P22-Ppid }{ }^{C-182 A} \text { upstream of } g f p \\
\text { in the pFPV25 plasmid }\end{array}$ & This study \\
\hline
\end{tabular}


Table 1. Cont.

\begin{tabular}{|c|c|c|}
\hline Name & Characteristic & $\begin{array}{l}\text { Source or } \\
\text { Reference }\end{array}$ \\
\hline pFPV-P22-Ppid ${ }^{\mathrm{C}-183 A_{-}-g f p}$ & $\begin{array}{c}\text { Contains } 521 \mathrm{bp} \text { of the } 5^{\prime} \text { regulatory region of P22-Ppid }{ }^{C-183 A} \text { upstream of } g f p \\
\text { in the pFPV25 plasmid }\end{array}$ & This study \\
\hline pFPV-P22-Ppid ${ }^{338}-g f p$ & $\begin{array}{l}\text { Contains } 338 \mathrm{bp} \text { of the } 5^{\prime} \text { regulatory region of P22wt upstream of } g f p \text { in the } \\
\text { pFPV25 plasmid }\end{array}$ & This study \\
\hline pFPV-P22-Ppid ${ }^{232}-g f p$ & $\begin{array}{c}\text { Contains } 232 \text { bp of the } 5^{\prime} \text { regulatory region of P22wt upstream of } g f p \text { in the } \\
\text { pFPV25 plasmid }\end{array}$ & This study \\
\hline
\end{tabular}

\subsection{Construction of Lysogens}

Lysogens were constructed by propagation of a phage on indicator strain LT2K7 via the double agar overlay method [34]. Cells within the turbid zone of a plaque were isolated and purified on green indicator plates [39] and plates were incubated for $15-20 \mathrm{~h}$ at $37^{\circ} \mathrm{C}$. Pale green colonies were selected and cross streaked across the respective phage on green indicator plates to confirm lysogenisation.

\subsection{Construction of Phage Mutants}

Amplicons used in the construction of phage mutants were obtained via PCR with Phusion DNA polymerase (Thermo Fisher Scientific, Waltham, MA, USA). Primers were synthesized by IDT (Leuven, Belgium) and are listed in Table 2.

Table 2. Primers used in the study.

\begin{tabular}{|c|c|}
\hline Primer Name & Sequence $\left(5^{\prime}-3^{\prime}\right)^{1}$ \\
\hline P22_Apid_Fw & $\begin{array}{l}\text { GTGATGATGCCGAGCACGCCCATCTGGACTATCTCAACTAGTCGATTCAT } \\
\text { ATTCCGGGGATCCGTCGACC }\end{array}$ \\
\hline P22_Apid_Rev & $\begin{array}{l}\text { CTTATACCATCGACTGGATATTATTCGTTTTATCCCGTCTATGTGGGGGGGGGGATAAAA } \\
\text { TGTAGGCTGGAGCTGCTTCG }\end{array}$ \\
\hline P22_pid_Fw & GTCAGGATCC ACAGGTCTAACGCTTCCC \\
\hline P22_pid_Rev & GATGTCTAGA GCATAAAGTTTCTTGTGGTTG \\
\hline P22_pid338_Fw & GTCAGGATCC ACTGGAATTTCTGTTCTTCAGTCA \\
\hline P22_pid232_Fw & GTCAGGATCC TCATGACATGTGTCACATTTATA \\
\hline P22_5UTRpid_tetAsacB_Fw & $\begin{array}{l}\text { ATATCTTCAAGGTGGGCAATTTTTTGCTCTATATCTGACATGTCCACTCCTTT } \\
\text { TCCTAATTTTTGTTGACACTCTATC }\end{array}$ \\
\hline P22_5UTRpid_tetAsacB_Revv & $\begin{array}{l}\text { ATTGCTTTAAGTTTACAGAACAATAATCCTTGGCTGGACGTAAGGTTTTGACA } \\
\text { ATCAAAGGGAAAACTGTCCATATGC }\end{array}$ \\
\hline P22_5UTR423pid_Fw & $\begin{array}{l}\text { ATATCTTCAAGGTGGGCAATTTTTTGCTCTATATCTGACATGTCCACTCCTTT } \\
\text { TCTGTCATGAGTACCTCATCG }\end{array}$ \\
\hline P22_5UTR371pid_Fw & $\begin{array}{l}\text { ATATCTTCAAGGTGGGCAATTTTTTGCTCTATATCTGACATGTCCACTCCTTT } \\
\text { GGAGATATCTAAGATTGC }\end{array}$ \\
\hline P22_5UTR331pid_Fw & $\begin{array}{c}\text { ATATCTTCAAGGTGGGCAATTTTTTGCTCTATATCTGACATGTCCACTCCTTT } \\
\text { TGTCAAAACCTTACGTCCAGCCAA }\end{array}$ \\
\hline P225UTRpid_Rev & GATTCATGACATGTGTCACATTTATACCAACCAGATCATTGCTTTAAGTTTAC \\
\hline Sal_5S_rRNA & TGGGACCACCGCGCTAGTGCCG \\
\hline Pid_5UTR & ATCTAAGATTGCTATCACACTGC \\
\hline Pid_ORF & GATAATATCTTCAAGGTGGGCA \\
\hline
\end{tabular}

${ }^{1}$ Primer attachment sites are indicated in bold. Restriction sites are shown in italics. Recombination regions are indicated in regular font. 
P22- $\Delta$ pid was constructed on the basis of the $\lambda$-red recombineering system, described by Datsenko and Wanner in the year 2000 [37]. The amplicon was generated via PCR

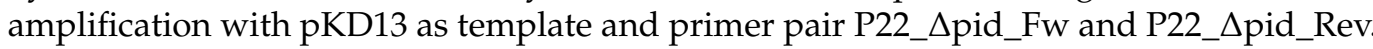
The introduced kanamycin cassette was subsequently flipped out with pCP20, which harbors Flp to recombine two frt-sites flanking the kanamycin gene [38].

Phage mutants P22-pid ${ }^{423}$, P22-pid ${ }^{371}$, and P22-pid ${ }^{331}$ were constructed on the basis of the $\lambda$-red recombineering system [37] and a two-step selection and counterselection process using the tet $A-s a c B$ cassette, described by Li et al. in the year 2013 [36]. The tet $A-s a c B$ cassette was amplified from E. coli XTL298 in a colony PCR with primers P22_5UTRpid_tetAsacB_Fw and P22_5UTRpid_tetAsacB_Rev. The obtained cassette was introduced in the 5'UTR region of pid via homologous recombination, replacing 13-157 bp upstream of the pid ORF. Correct clones were selected on tetracycline LB agar plates. The tet $A-s a c B$ cassette was subsequently substituted via homologous recombination with the truncated 5'UTR amplicons obtained via either primer pairs P22_5UTR423pid_Fw and P225UTRpid_Rev, P22_5UTR371pid_Fw and P225UTRpid_Rev, or P22_5UTR331pid_Fw and P225UTRpid_Rev. Correct clones were selected on counterselection agar plates and validated via Sanger sequencing (Macrogen Europe B.V., Amsterdam, the Netherlands).

\subsection{Construction of Plasmids}

The inserts that were ligated in the vectors were obtained via PCR with Phusion DNA polymerase (Thermo Fisher Scientific, Waltham, MA, USA). Primers were synthesized by IDT (Leuven, Belgium) and can be found in Table 2. Constructs were validated via Sanger sequencing (Macrogen Europe B.V., Amsterdam, the Netherlands).

Plasmids pFPV-P22-Ppid ${ }^{w t}-g f p$, pFPV-P22-Ppid ${ }^{C-182 A_{-}} g f p$, and pFPV-P22-Ppid ${ }^{C-183 A_{-}-g f p}$ were constructed by digesting pFPV25 with XbaI and BamHI (Thermo Fisher Scientific, Waltham, MA, USA). The digested vector was subsequently ligated with the (mutated) $5^{\prime}$ regulatory region of pid. The latter amplicon was obtained using primers P22_pid_Fw and P22_pid_Rev and digested with XbaI and BamHI, prior to ligation.

Plasmids pFPV-P22-Ppid ${ }^{338}-g f p$ and pFPV-P22-Ppid ${ }^{232}-g f p$ were constructed by digesting pFPV25 with XbaI and BamHI (Thermo Fisher Scientific, Waltham, MA, USA). The digested vector was subsequently ligated with a truncated $5^{\prime}$ regulatory region of pid of either $338 \mathrm{bp}$ or $232 \mathrm{bp}$. The latter amplicons were obtained, respectively, using primer pairs P22_pid338_Fw and P22_pid_Rev or P22_pid232_Fw and P22_pid_Rev, and digested with $\mathrm{XbaI}$ and BamHI prior to ligation.

\subsection{DES-Mutagenesis Screen}

To screen for mutants in P22, we added $50 \mu \mathrm{L}$ of the mutagen diethylsulfate (DES) to $50 \mu \mathrm{L}$ of LT2 [P22] stationary phase culture and the mixture was incubated for $50 \mathrm{~min}$ at $37^{\circ} \mathrm{C}$ without shaking. Next, $50 \mu \mathrm{L}$ of the mixture was added to $2 \mathrm{~mL}$ of LB broth and grown for $6 \mathrm{~h}$ at $37^{\circ} \mathrm{C}$ under shaking conditions. Phages were extracted and propagated on LT2 as plaques in LB soft agar or as lysates in LB. This procedure was repeated eight times to obtain eight pools of mutagenized phage lysate. The mutagenized phage lysate was propagated on stationary phase culture of LT2K7 on green indicator plates [39]. After overnight incubation, each indicator plate was replica plated on a new indicator plate and on a LB agar plate containing X-Gal. In total, 39,950 plaques were screened on LB agar plates supplemented with $40 \mu \mathrm{g} / \mathrm{mL}$ X-Gal and 26,740 plaques on LB agar plates supplemented with $20 \mu \mathrm{g} / \mathrm{mL}$ X-Gal, allowing the identification of more blue phenotypes compared to wild-type P22.

\section{6. $\beta$-Galactosidase Assay}

Expression of $\beta$-galactosidase (LacZ) was visualized by adding 5-bromo-4-chloro3-indolyl- $\beta$-D-galactopyranoside (X-Gal) to agar plates $(40 \mu \mathrm{g} / \mathrm{mL})$. $\beta$-Galactosidase hydrolyses $X-G a l$ to an insoluble blue precipitate. For clear visualization of spotted phage 
populations, we pressed agar plates onto Whatman filter papers (GE Healthcare, Chicago, IL, USA) before photographing them.

\subsection{Fluorescence Population Level Measurement}

Population-level fluorescence measurements were obtained in a Fluoroskan Ascent FL (Thermo Fisher Scientific, Waltham, MA, USA), equipped with a filter pair with an excitation wavelength of $485 \mathrm{~nm}$ and an emission wavelength of $520 \mathrm{~nm}$. A multi-well microtiter plate was filled with $200 \mu \mathrm{L}$ of stationary phase cultures grown in AB-glucose medium $\left(2 \mathrm{~g} / \mathrm{L}\left(\mathrm{NH}_{4}\right)_{2} \mathrm{SO}_{4}, 6 \mathrm{~g} / \mathrm{L} \mathrm{Na}_{2} \mathrm{HPO}_{4}, 3 \mathrm{~g} / \mathrm{L} \mathrm{KH}_{2} \mathrm{PO}_{4}, 3 \mathrm{~g} / \mathrm{L} \mathrm{NaCl}, 0.1 \mathrm{mM} \mathrm{CaCl}\right.$, $1.0 \mathrm{mM} \mathrm{MgCl}_{2}$, and $0.003 \mathrm{mM} \mathrm{FeCl}_{3}$ [40] and supplemented with $0.2 \%$ D-glucose, $1 \mu \mathrm{g} / \mathrm{mL}$ uracil, and $1 \mu \mathrm{g} / \mathrm{mL}$ thiamine and $0.2 \%$ casamino acids). The obtained fluorescence values were subsequently normalized over the optical density at $\mathrm{OD}_{600}$ of the sample (obtained via the Multiskan RC, Thermo Labsystems OY, Helsinki, Finland).

\subsection{Statistical Analysis}

All fluorescence measurements were performed in triplicate. Statistical analyses, histograms, and Tukey HSD tests $(p=0.05)$ were carried out using the JMP software (version Pro 15.1.0; SAS, Cary, NC, USA), and differences were considered significant when $p \leq 0.05$.

\subsection{Northern Blotting}

Exponential phase cultures of $S$. Typhimurium LT2 were infected with P22wt, P22-

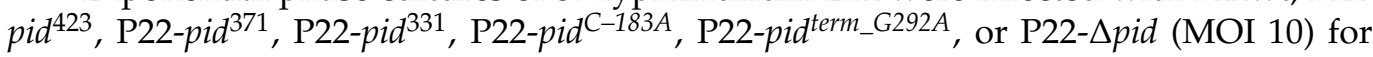
$90 \mathrm{~min}$. Infection was stopped by adding $20 \%$ volume of stop mixture $(95 \% \mathrm{EtOH}, 5 \%$ phenol; $\mathrm{pH}$ 5.5), followed by snap-freezing in liquid nitrogen. Following this, total RNA was extracted according to the hot phenol method, and the remaining DNA was digested via DNase I treatment (Thermo Fisher Scientific, Waltham, MA, USA). Subsequently, $7 \mu \mathrm{g}$ of total RNA per sample was resolved on a $6 \%$ polyacrylamide gel containing $7 \mathrm{M}$ urea and transferred to an Amersham Hybond-XL (GE Healthcare, Chicago, IL, USA) membrane. After UV-crosslinking, transcripts of interest were detected by radiolabeled oligonucleotides Sal_5S_rRNA (5S rRNA probe for loading control), Pid_5UTR, and/or Pid_ORF (Table 2). The labelling reaction was carried out as follows: 10 pmol of the oligonucleotides were $5^{\prime}$-labeled with $10 \mu \mathrm{Ci}{ }^{32} \mathrm{P}-\gamma$-ATP (Perkin Elmer, Waltham, MA, USA) by T4 polynucleotide kinase (PNK, Thermo Fisher Scientific, Waltham, MA, USA) for $1 \mathrm{~h}$ at $37^{\circ} \mathrm{C}$. After removing unincorporated ${ }^{32} \mathrm{P}-\gamma$-ATP with a Microspin G-25 column (GE Healthcare, Chicago, IL, USA), $7 \mu \mathrm{L}$ of the labelled oligonucleotide was added to $17 \mathrm{~mL}$ EKONO hybridization buffer (G-Biosciences, Saint Louis, MI, USA) and hybridized to the membrane, overnight at $42{ }^{\circ} \mathrm{C}$ in a hybridization oven. Radioactive signals were imaged with a Typhoon 9400 (Variable Mode Imager, Amersham Biosciences, Amersham, United Kingdom), and the membrane was stripped for re-probing by immersing it in $500 \mathrm{~mL}$ hot $\mathrm{H}_{2} \mathrm{O} / 5 \mathrm{~mL} 10 \%$ SDS for $7 \mathrm{~min}$.

Author Contributions: Conceptualization, S.W., A.M., W.C. and A.A.; formal analysis, S.W., Y.B., N.A.W. and S.V.O.; funding acquisition, R.L. and A.A.; investigation, S.W., A.M., L.W., L.E.B., W.C., N.A.W. and S.V.O.; project administration, S.W. and A.A.; supervision, R.L. and A.A.; validation, S.W., A.M., L.W. and L.E.B.; visualization, S.W. and S.V.O.; writing-original draft, S.W. and A.A.; writing-review and editing, S.W., A.M., L.W., L.E.B., W.C., Y.B., N.A.W., S.V.O., J.C.D.H., R.L. and A.A. All authors have read and agreed to the published version of the manuscript.

Funding: This research was funded by doctoral fellowships from Fonds Wetenschappelijk Onderzoek Vlaanderen, grant numbers 11H0321N (L.B.) and 11D8920N (L.W.); by a postdoctoral fellowship by the KU Leuven Research Fund, grant number PDMK/14/138 (W.C.); and through project grants from the KU Leuven Research Fund, grant numbers GOA/15/006 and C14/20/087.

Institutional Review Board Statement: Not applicable.

Informed Consent Statement: Not applicable. 
Data Availability Statement: The data presented in this study are available on request from the corresponding author.

Acknowledgments: The authors would like to thank Alaa Albasiony for help with spot plating of the P22 lysogens (Figure 3).

Conflicts of Interest: The authors declare no conflict of interest. The funders had no role in the design of the study; in the collection, analyses, or interpretation of data; in the writing of the manuscript; or in the decision to publish the results.

\section{References}

1. Comeau, A.M.; Hatfull, G.F.; Krisch, H.M.; Lindell, D.; Mann, N.H.; Prangishvili, D. Exploring the prokaryotic virosphere. Res. Microbiol. 2008, 159, 306-313. [CrossRef] [PubMed]

2. Koskella, B.; Brockhurst, M.A. Bacteria-phage coevolution as a driver of ecological and evolutionary processes in microbial communities. FEMS Microbiol. Rev. 2014, 38, 916-931. [CrossRef] [PubMed]

3. Angly, F.E.; Felts, B.; Breitbart, M.; Salamon, P.; Edwards, R.A.; Carlson, C.; Chan, A.M.; Haynes, M.; Kelley, S.; Liu, H.; et al. The marine viromes of four oceanic regions. PLoS Biol. 2006, 4, 2121-2131. [CrossRef] [PubMed]

4. Yin, Y.; Fischer, D. Identification and investigation of ORFans in the viral world. BMC Genom. 2008, 9, 24. [CrossRef] [PubMed]

5. Filipa-Silva, A.; Parreira, R.; Martínez-Puchol, S.; Bofill-Mas, S.; Crespo, M.T.B.; Nunes, M. The Unexplored Virome of Two Atlantic Coast Fish: Contribution of Next-Generation Sequencing to Fish Virology. Foods 2020, 9, 1634. [CrossRef]

6. $\quad$ Owen, S.V.; Canals, R.; Wenner, N.; Hammarlöf, D.L.; Kröger, C.; Hinton, J.C.D. A window into lysogeny: Revealing temperate phage biology with transcriptomics. Microb. Genom. 2020, 6, e000330. [CrossRef]

7. Ang, D.; Georgopoulos, C. An orfan no more: The bacteriophage T4 39.2 gene product, NWGI, modulates GroEL chaperone function. Genetics 2012, 190, 989-1000. [CrossRef]

8. Boon, M.; De Zitter, E.; De Smet, J.; Wagemans, J.; Voet, M.; Pennemann, F.L.; Schalck, T.; Kuznedelov, K.; Severinov, K.; Van Meervelt, L.; et al. 'Drc', a structurally novel ssDNA-binding transcription regulator of N4-related bacterial viruses. Nucleic Acids Res. 2020, 48, 445-459. [CrossRef]

9. Wagemans, J.; Blasdel, B.G.; Van den Bossche, A.; Uytterhoeven, B.; De Smet, J.; Paeshuyse, J.; Cenens, W.; Aertsen, A.; Uetz, P.; Delattre, A.S.; et al. Functional elucidation of antibacterial phage ORFans targeting Pseudomonas aeruginosa. Cell. Microbiol. 2014, 16, 1822-1835. [CrossRef]

10. Mattenberger, Y.; Silva, F.; Belin, D. 55.2 a phage T4 ORFan gene, encodes an inhibitor of Escherichia coli topoisomerase I, increases phage fitness. PLoS ONE 2015, 10, e0124309. [CrossRef]

11. Cenens, W.; Makumi, A.; Govers, S.K.; Lavigne, R.; Aertsen, A. Viral Transmission Dynamics at Single-Cell Resolution Reveal Transiently Immune Subpopulations Caused by a Carrier State Association. PLoS Genet. 2015, 11, e1005770. [CrossRef] [PubMed]

12. Cenens, W.; Mebrhatu, M.T.; Makumi, A.; Ceyssens, P.J.; Lavigne, R.; Van Houdt, R.; Taddei, F.; Aertsen, A. Expression of a Novel P22 ORFan Gene Reveals the Phage Carrier State in Salmonella Typhimurium. PLoS Genet. 2013, 9, e1003269. [CrossRef] [PubMed]

13. Abe, H.; Aiba, H. Differential contributions of two elements of rho-independent terminator to transcription termination and mRNA stabilization. Biochimie 1996, 78, 1035-1042. [CrossRef]

14. Wilson, K.S.; von Hippel, P.H. Transcription termination at intrinsic terminators: The role of the RNA hairpin. Proc. Natl. Acad. Sci. USA 1995, 92, 8793-8797. [CrossRef] [PubMed]

15. Afgan, E.; Baker, D.; Batut, B.; Van Den Beek, M.; Bouvier, D.; Čech, M.; Chilton, J.; Clements, D.; Coraor, N.; Grüning, B.A.; et al. The Galaxy platform for accessible, reproducible and collaborative biomedical analyses: 2018 update. Nucleic Acids Res. 2018, 46, W537-W544. [CrossRef]

16. Coppens, L.; Lavigne, R. SAPPHIRE: A neural network based classifier for $\sigma 70$ promoter prediction in Pseudomonas. BMC Bioinform. 2020, 21, 415. [CrossRef]

17. Valdivia, R.H.; Falkow, S. Fluorescence-based isolation of bacterial genes expressed within host cells. Science 1997, $277,2007-2011$. [CrossRef]

18. Fournier, B.; Lu, C.Y.; Lagrange, P.H.; Krishnamoorthy, R.; Philippon, A. Point mutation in the Pribnow box, the molecular basis of $\beta$-lactamase overproduction in Klebsiella oxytoca. Antimicrob. Agents Chemother. 1995, 39, 1365-1368. [CrossRef]

19. Chapon, C. Expression of malT, the regulator gene of the maltose region in Escherichia coli, is limited both at transcription and translation. EMBO J. 1982, 1, 369-374. [CrossRef]

20. Kingsley, R.A.; Msefula, C.L.; Thomson, N.R.; Kariuki, S.; Holt, K.E.; Gordon, M.A.; Harris, D.; Clarke, L.; Whitehead, S.; Sangal, V.; et al. Epidemic multiple drug resistant Salmonella Typhimurium causing invasive disease in sub-Saharan Africa have a distinct genotype. Genome Res. 2009, 19, 2279-2287. [CrossRef]

21. Hammarlöf, D.L.; Kröger, C.; Owen, S.V.; Canals, R.; Lacharme-Lora, L.; Wenner, N.; Schager, A.E.; Wells, T.J.; Henderson, I.R.; Wigley, P.; et al. Role of a single noncoding nucleotide in the evolution of an epidemic African clade of Salmonella. Proc. Natl. Acad. Sci. USA 2018, 115, E2614-E2623. [CrossRef] [PubMed] 
22. Canals, R.; Hammarlöf, D.L.; Kröger, C.; Owen, S.V.; Fong, W.Y.; Lacharme-Lora, L.; Zhu, X.; Wenner, N.; Carden, S.E.; Honeycutt, J.; et al. Adding function to the genome of African Salmonella Typhimurium ST313 strain D23580. PLoS Biol. 2019, 17, e3000059. [CrossRef] [PubMed]

23. Chen, L.H.; Emory, S.A.; Bricker, A.L.; Bouvet, P.; Belasco, J.G. Structure and function of a bacterial mRNA stabilizer: Analysis of the $5^{\prime}$ untranslated region of ompA mRNA. J. Bacteriol. 1991, 173, 4578-4586. [CrossRef] [PubMed]

24. Arnold, T.E.; Yu, J.; Belasco, J.G. mRNA stabilization by the ompA $5^{\prime}$ untranslated region: Two protective elements hinder distinct pathways for mRNA degradation. RNA 1998, 4, 319-330. [PubMed]

25. Cao, Y.; Li, J.; Jiang, N.; Dong, X. Mechanism for stabilizing mRNAs involved in methanol-dependent methanogenesis of cold-adaptive Methanosarcina mazei zm-15. Appl. Environ. Microbiol. 2014, 80, 1291-1298. [CrossRef] [PubMed]

26. Wu, Q.; Mao, X.H. The $5^{\prime}$ untranslated region of fruA mRNA in Myxococcus xanthus positively regulates the expression of its own gene. Chin. Sci. Bull. 2004, 49, 2266-2271. [CrossRef]

27. Jian, H.; Xiong, L.; Xu, G.; Xiao, X.; Wang, F. Long 5' untranslated regions regulate the RNA stability of the deep-sea filamentous phage SW1. Sci. Rep. 2016, 6, 21908. [CrossRef]

28. Belin, D.; Mudd, E.A.; Prentki, P.; Yi-Yi, Y.; Krisch, H.M. Sense and antisense transcription of bacteriophage T4 gene 32. Processing and stability of the mRNAs. J. Mol. Biol. 1987, 194, 231-243. [CrossRef]

29. Lioliou, E.; Sharma, C.M.; Caldelari, I.; Helfer, A.C.; Fechter, P.; Vandenesch, F.; Vogel, J.; Romby, P. Global regulatory functions of the Staphylococcus aureus endoribonuclease III in gene expression. PLoS Genet. 2012, 8, e1002782. [CrossRef]

30. Obana, N.; Shirahama, Y.; Abe, K.; Nakamura, K. Stabilization of Clostridium perfringens collagenase mRNA by VR-RNAdependent cleavage in $5^{\prime}$ leader sequence. Mol. Microbiol. 2010, 77, 1416-1428. [CrossRef]

31. Martínez-Trujillo, M.; Sanchez-Trujillo, A.; Ceja, V.; Ávila-Moreno, F. Sequences required for transcription termination at the intrinsic $\lambda$ tI terminator. Can. J. Microbiol. 2010, 56, 168-177. [CrossRef] [PubMed]

32. Cisneros, B.; Court, D.; Sanchez, A.; Montañez, C. Point mutations in a transcription terminator, $\lambda \mathrm{tI}$, that affect both transcription termination and RNA stability. Gene 1996, 181, 127-133. [CrossRef]

33. Sambrook, J.; Russell, D.W. Molecular Cloning (a Laboratory Manual); Cold Spring Harbor Laboratory Press: New York, NY, USA, 2001

34. Adams, M.H. Bacteriophages; Interscience Publishers: New York, NY, USA, 1959.

35. McClelland, M.; Sanderson, K.E.; Spieth, J.; Clifton, S.W.; Latreille, P.; Courtney, L.; Porwollik, S.; Ali, J.; Dante, M.; Du, F.; et al. Complete genome sequence of Salmonella enterica serovar Typhimurium LT2. Nature 2001, 413, 852-856. [CrossRef] [PubMed]

36. Li, X.T.; Thomason, L.C.; Sawitzke, J.A.; Costantino, N.; Court, D.L. Positive and negative selection using the tetA-sacB cassette: Recombineering and P1 transduction in Escherichia coli. Nucleic Acids Res. 2013, 41, 1-8. [CrossRef] [PubMed]

37. Datsenko, K.A.; Wanner, B.L. One-step inactivation of chromosomal genes in Escherichia coli K-12 using PCR products. Proc. Natl. Acad. Sci. USA 2000, 97, 6640-6645. [CrossRef] [PubMed]

38. Cherepanov, P.P.; Wackernagel, W. Gene disruption in Escherichia coli: TcR and KmR cassettes with the option of Flp-catalyzed excision of the antibiotic-resistance determinant. Gene 1995, 158, 9-14. [CrossRef]

39. Davis, R.; Botstein, D.; Roth, J. Advanced Bacterial Genetics; Cold Spring Harbor Laboratory Press: New York, NY, USA, 1980.

40. Clark, D.J.; Maaløe, O. DNA replication and the division cycle in Escherichia coli. J. Mol. Biol. 1967, 23, 99-112. [CrossRef] 